\title{
Painful invisibilities: Roll management or 'off-rolling' and professional identity
}

\author{
Elizabeth J. Done* and Helen Knowler \\ Plymouth Institute of Education, University of Plymouth, Drake Circus, Plymouth, PLA 8AA. \\ Graduate School of Education, University of Exeter, St Luke's Campus, Heavitree Road,
}

Exeter, EX1 2LU. Tel. +44 (0)1392 724934. Corresponding author:

elizabeth.done@plymouth.ac.uk

Accepted for publication $15^{\text {th }}$ November 2019

\begin{abstract}
'Off-rolling' is widely defined as the illegal removal of students from a school roll unlike permanent exclusion which involves sanctioned formal procedures. It is a practice that brings very different logics, political agendas, governmental imperatives and the associated matter of school leader professional identity into sharp relief. Deviant professional identities have already been discursively constituted despite the current lack of research into the motivation of senior school leaders who engage in 'off-rolling'. This paper draws on Foucault to explore tensions between a political standards and an inclusion agenda, and to consider how the professional identities of senior school leaders are shaped such that 'off-rolling' becomes possible. It is suggested that chronic under-funding of the inclusion agenda has combined with what England's Office for Standards in Education, Children's Services and Skills (Ofsted) now describes as an overemphasis on academic performance to create unsustainable pressures on many senior school leaders. The descriptor 'contextual roll management' may therefore be more appropriate. The moral outrage which accompanies public and political discourse around 'off-rolling' is theorised with reference to Apple, Ball and Popkewitz. Such moral indignation distracts attention from the wider socio-political and economic context within which schools are now required to deliver academic progress and inclusion. We conclude the paper by outlining key empirical questions that have yet to be addressed.
\end{abstract}

Key words: 'off-rolling'; roll management; inclusion; professional identity; educational policy

\section{Introduction}

The title of this paper alludes to the potentially 'painful' consequences of school exclusion for the excluded but also to the invisibility of senior school leaders beyond their roles as the suppliers of school data and objects of moral condemnation in accounts of an exclusionary and illegal practice referred to as 'off-rolling' in England. This alleged practice involves the removal of students from the school roll where removal is in the interests of the school not the student. The authors reject historicist explanations of 'off-rolling' as yet another variant of exclusion conceived as a trans-historical universal constant and, instead, suggest that the intelligibility of 'off-rolling' as a novel historical practice involves showing it to be possible within a historically-specific dispositif (arrangement of social relations) (Foucault 2008). The prevailing neoliberal marketised educational culture and attendant accountability regime have not only made 'off-rolling' possible, they have incentivised senior school leaders to engage in such practices even though the majority choose not to do so (Department for Education [DfE] 
2019a). It has been reported that $43 \%$ of state-funded secondary schools did not issue any formal permanent exclusions in 2016-17 but that the government has yet to determine the scale of 'off-rolling' (DfE 2019a, 9, 11). Using school census data, Ofsted (2019a) calculate that 19,00 pupils left their state-funded secondary school between year 10 in January 2016 and year 11 in January 2017 with approximately half remaining unaccounted for; the number of secondary schools in England where 'off rolling' is strongly suspected - based on such census data, rose from 300 to 340 in the following year. Our priority here, however, is not quantifying 'off rolling' but, rather, developing a typology of representations of senior school leaders in public discourse relating to the practice and conceptual framework for analytical purposes.

\section{Painful invisibilities}

The phrase 'painful invisibilities' derives from Apple's (2014: vii) observation that the political classes of England, Australia and the United States seem oblivious to the numerous 'areas of pain' that have been produced by neo-liberalising processes, including the remaking of the public sector in response to the 'exigencies of globalization' and national economic priorities (Ball 2008, 15 cited in Apple 2014, vii); discourses associated with these processes render 'all of the pain invisible' (Apple 2014: viii). Anecdotal and data-based evidence that supports suspicions of 'off-rolling' is publicly available through, for example, reports from Local Authorities to the Office of the Schools' Adjudicator (OSA 2018) and the Family Fisher Trust (Nye 2017; Thomson 2018) respectively. Most recently, the Timpson Review (DfE 2019a) has noted similarly anecdotal evidence whilst in a survey commissioned by Ofsted $64 \%$ of teachers surveyed responded that 'off-rolling' occurred 'a lot' or a 'fair amount' (YouGov 2019). However, the illegal nature of this practice will ensure that senior leaders are reluctant to engage in public dialogue around the topic. We consider it to be highly unlikely that senior school leaders engage in illegal 'off-rolling' without careful consideration of the risks involved and our research (to be reported in 2020) is designed to explore the pressures which prompt some to pursue this course of action and how doing so might affect their professional identities.

\section{Compartmentalisation}

Following Popkewitz (1984, 174), Munn and Lloyd (2005, 206) and Sellman et al. (2002), our objective in this paper is to insist on a theory of context; one that precludes moralistic 'teacher-blaming' (Thrupp 1998) and demands a descriptor that is less pejorative than 'offrolling'. Just as instrumental educational research has become focused on narrowly defined areas (Popkewitz 1991), policy-making is similarly compartmentalised insofar as policy makers in one area are under no obligation to consider how compatible their proposed policies will be with existing or planned policies in another domain. Instead, the emphasis in neoliberal educational cultures is on the "constant production of evidence that one is doing "the right thing"' (Apple 2014, ix) regardless of perceived tensions between policy areas. The state does not require evidence of a capacity to reconcile divergent policy areas at practice level but this is precisely what senior school leaders must do if they are to optimise a school's academic performance and be meaningfully inclusive.

In the absence of research which attends to the experience of senior leaders who engage in 'off-rolling' it cannot be presumed that the prioritising of academic performance and related reputational data indicators implies non-subscription to a socio-political discourse around social justice and inclusion. It is noteworthy then that varied 'kinds' of professional identity have already been constituted in the public discourse surrounding 'off-rolling'; following Foucault $(2008,19)$, these have been 'marked out in reality' prior to punitive or ameliorative governmental initiatives and, most importantly, prior to substantiated prevalence data. Foucault (1977) refers to this process of constitution as fabrication; it involves the production of images or representations which carry a certain disciplinary force in both the public and 
private domains insofar as they influence, in this instance, how senior school leaders are perceived by others and how they may perceive themselves.

Three such 'kinds' of identity are currently circulating, including, the system gamer and the poor behaviour manager, and the process through which they have evolved is not dissimilar to that posited by Popkewitz (2013). Data analysis functions as an engine of discovery 'having to do with finding out the facts' but equally becomes an engine for 'making up people' (Hacking 2006). Once relevant data has been found and the scale of a putative problem quantified or estimated, deviant identities are formulated (Popkewitz 2013). These identities are explored in a later section of this paper and contrasted with a third 'kind' which we characterise as the 'best practice' exemplar.

\section{New accountabilities}

The Timpson Review (2019a) was commissioned by the Conservative government and its recommendations are designed to address rising rates of permanent and fixed term exclusions in England, differential rates of exclusion between specific categories of student and the practice of 'off rolling'. The government response (DfE 2019b) exemplifies neoliberal education governance as a tension between centralising and decentralising tendencies (Ball and Junemann 2011). The professional autonomy of school principals, demonstrated in their decision-making around exclusion, will continue to be supported; and yet control and oversight will be centralised and intensified through proposed 'new accountabilities' for schools and other bodies (DfE 2019b, 7). This follows a recent rise in school exclusion rates and suggestions that some senior school leaders have evolved their own strategies for maintaining or improving their school's position in academic performance league tables and other publicly available data-based indicators of a successful school such as low rates of absenteeism and permanent exclusion. Ofsted (2019b), the body that inspects England's schools, can now identify those schools that may be engaging in illegal exclusionary practices by calculating student moves which exceed expected levels. It is not yet clear, however, whether these are schools with student populations possessing high levels of social capital that are seeking to maintain high performance ratings and market position; or whether they are poorly performing schools seeking to improve that position and avoid sanction; or whether there is no such discernible pattern. The claim that multi-academy trusts (MATs) are over-represented amongst 'off-rolling' schools (The Times 2019) is rejected by Timpson (DfE 2019a). What is clear is that specific categories of student are far more likely to be excluded (Ofsted 2018). In evidence presented to Timpson, $78 \%$ of formal permanent exclusions issued were to children classified as: having 'special educational needs', being disadvantaged (children deemed in need or eligible for free school meals), and of 'Black Caribbean' or 'Mixed White and Black Caribbean' ethnicity; boys are also more likely to be excluded but this depends on the presence of these characteristics (DfE 2019a, 9-10). Similar correlations have been posited in the case of 'off-rolling' (Ofsted 2018, 2019b, 50). It has also been suggested that a proportion of the $70 \%$ increase in 'elective home education' in some Local Authorities is, in fact, due to coercion on the part of schools (OSA 2018).

We would suggest that the recent proliferation of exclusionary practices, both legal (e.g. managed moves, placement in alternative provision) and illegal, is a function of the tension between policy imperatives, that is, between policies implying very different logics such that reconciling them in practice may be challenging. A political standards agenda is privileged and reinforced through marketisation and, consequently, the equally political social justice and inclusion agenda cannot be meaningfully realised. Nevertheless, senior school leaders, and the teaching profession more generally, are required to demonstrate their capacity to deliver both and penalised when unable to do so. The new 'common sense' (Popkewitz 2013, 443) of neoliberal educational culture is that the logics of competition and inclusion are entirely compatible if only senior school leaders are sufficiently 'responsibilised' (Foucault 
1982, 781) and intensively scrutinized. Responsibilisation here not only implies being held to account for the realisation of policy objectives but, equally importantly, the instilling of a deep-seated sense of personal responsibility for outcomes. The government has proposed that, in future, schools will be held accountable for excluded students' outcomes to discourage 'off-rolling'; and new mechanisms, such as local forums involving Local Authorities, governing bodies, schools and alternative provision providers, will be introduced with the remit of monitoring trends to prevent children slipping through the net (DfE 2019b) or exclusion 'through the back door' (DfE 2019a, 85).

\section{'Off-rolling'}

\section{Prevalence}

The term 'off-rolling' describes the practice of removing pupils from a school roll without observing sanctioned and legal procedures for permanent school exclusion (Ofsted 2019c, 50). Recently developed statistical modelling has identified that a proportion of pupils who leave English schools prematurely remain unaccounted for (Ofsted 2018). The 'missing' are those pupils who are not subsequently registered for home education or enrolled at another school or educational setting and it is estimated that 9,700 pupils fell into this category between January 2016 and January 2017 (Ofsted 2019b, 50). As previously mentioned, there have also been suggestions that an as yet unknown proportion of elective home educators are, in fact, coerced or pressurised by schools into withdrawing their children from school even though they are ill-equipped to home educate (OSA 2018, 35). Additionally, some very young children with disabilities or diagnosed conditions are declined initial admission to schools (Ofsted 2019b) in a form of pre-emptive 'off-rolling', despite their legal right to mainstream education following the Children and Families Act (DfE 2014).

Ofsted can now interrogate national data to identify 'exceptional movements' (schools where an unexpectedly high number of pupils have left prematurely) and is currently training its school inspectors to 'ask pertinent questions' where 'off-rolling' is suspected $(2019 \mathrm{~b}, 27)$. Schools found to be 'off-rolling' will be given an 'inadequate' judgement at inspection (DfE 2019a, 15). The recent publication of similar data analysis by the Education Policy Institute (EPI 2019) was accompanied by calls from the organisation's executive chairperson that the worst offending schools in this 'national scandal' be 'named and shamed' (The Times 18 April 2019, 26). The EPI's methodology permitted the identification of some risk factors but was unable to isolate data pertaining to special educational needs and disabilities (SEND) even though Ofsted (2018) has demonstrated that SEND-designated children are significantly over-represented within the sub-population where 'off-rolling' is suspected; hence, $30 \%$ of pupils who leave school in Years 10 and 11 are SEND-designated against 13\% nationally. Timpson's (DfE 2019a) findings also point to the over-representation of such students amongst the 'off-rolled'.

\section{Inclusion}

Under new leadership, Ofsted has proposed modifications to its school inspection criteria and the revised inspection framework seeks to address Ofsted's concerns relating to 'equalities, diversity and inclusion' (2019b, 3). Progress 8, a compulsory assessment of pupil performance across eight 'core' subjects introduced in 2016 (DfE 2016, 2017), is recognised as narrowing the curriculum and Ofsted (2019c) now regards such narrowing as unlawful discrimination against those with designated SEND under the Equality Act 2010. Ofsted is also seeking to end the 'pressure on parents to remove low attaining pupils from the school roll in order to protect the school's progress scores and examination results' $(2019 \mathrm{c}, 4)$. The four proposed key inspection 'judgement areas' are given as 'quality of education', 'behaviour and attitudes', 'personal development' and 'leadership and management' (Ofsted 2019c, 4). Ofsted (2018) follows Parsons (1999) in acknowledging that moral exhortation alone is unlikely to bring about the demise of exclusionary practices and in recognising the 
imbalances created by the historical emphasis on academic performance. There is, however, no suggestion that the latter will change; the implication is that schools must deliver on both agendas.

In England, following the introduction of the Children and Families Act 2014, senior school leaders must fulfil a school's legal requirement to accept children with SEND whose parents elect for mainstream education. Currently, meeting this requirement can have an adverse effect on school performance data (Nye 2017) and on school finances. The legislation in question permitted economic inefficiency as grounds for declining access (Done, Murphy and Knowler 2015) and, given that budgetary constraints on state-maintained schools are now more pronounced than ever, schools may be compelled to limit the number of children requiring additional support despite a commitment to educational inclusion. This situation has resulted in parents initiating legal actions against Local Authorities who continue to be legally responsible for the placement of such children despite significantly reduced central funding and a central government-led academisation programme which permits schools to report directly to the Department for Education and bypass local control. It is worth raising this issue in the context of school exclusion and 'off-rolling' because it highlights the plight of senior school leaders who would prefer to exercise 'advocacy leadership' (Anderson 2009) and be responsive to the needs of their local communities. Fiscal constraint and an associated discourse of economic realism have produced a situation in which many schools are struggling to fulfil their legal obligation to be inclusive (Tickle 2019) whilst simultaneously being subjected to closer governmental scrutiny through 'new accountabilities' (DfE 2019b, 7). There is currently no funding made available to schools that accept previously excluded or 'off-rolled' students (DfE 2019a, 86).

Critical analysts of educational and social exclusion are unlikely to be surprised by the identification of 'off-rolling' as a novel historical practice. As Slee states, the achievement of educational inclusion should be regarded as 'unfinished business' $(2018,7)$; it is inhibited by factors which include an appropriation of the discourse of inclusion 'by deeply conservative forces committed to sustaining exclusion and the ethic of competitive individualism that is the engine for education policymaking and school level practices' $(2019,1)$. On Slee's (2019) account, Ofsted's (2019b, 2019c) pronouncement that academic attainment has been overemphasised in recent years and prioritised over the implementation of inclusion-related legislation and guidance appears somewhat disingenuous. Similarly, a recent House of Commons Education Committee (HoCEC 2018, 40) report has simply recommended altering Progress 8 weighting used to calculate school performance to encourage inclusivity, which hardly suggests a fundamental overhaul of accountability practices or a rejection of the competitive individualism noted by Slee (2019).

\section{Moral outrage}

The discourse around 'off-rolling' conveys a powerful sense of moral outrage. Such expressions of moral indignation may be due, in part, to the apparent contradiction of wider social trends by 'off-rolling'. The illegality of the practice runs counter to a prevailing work culture of 'increasing rationalization' and 'a more sophisticated level of [workforce] control' (Apple 1995, 140), and to the associated expectations of a 'rules orientation' and 'greater dependability' in the application of politically sanctioned goals and values (p. 141).

Alternatively, non-compliance with inclusion-related legislation and guidance on the part of senior school leaders can be read as indicative of a selective and excessive internalisation, and subsequent prioritisation, of specific political goals; that is, as an intelligible response to the alleged over-emphasis on academic attainment (Ofsted 2019c) within a marketised educational system in which performance matters. Furthermore, a key feature of inclusionrelated political discourse identified in Slee and Allan's (2001) seminal analysis is the presentation of educational inclusion as something that has already become institutionalised. 
The recent discovery of evidence to the contrary through 'off-rolling' is, therefore, likely to offend a deeply-seated social belief in historical development as progress (Popkewitz 1991) with those engaging in 'off-rolling', accordingly, being perceived as either inhibiting progress towards educational inclusion or undermining the credibility of an established discourse of social amelioration and educational inclusivity.

\section{Evaluation and moral judgement}

Popkewitz's $(1984,171)$ analysis of accountability and the proliferation of evaluative techniques in education that focus on the 'observable and quantifiable' remains pertinent and, in the context of 'off-rolling', provides an explanation of the moral outrage provoked by this practice that is similar to Apple's (1995) account of late capitalist work cultures and concomitant developments within education. 'Schools are defined as production-orientated institutions to be managed by precise standards and techniques that direct, predict, and control all the activities of the organization' (Popkewitz 1984, 170). Comparative evaluation of schools, nationally and locally, is designed to deliver conformity to predetermined models and it is premised on an assumption that human behaviour can, and will, be engineered (Popkewitz 1984 170). The current socially and politically desired senior school leader is one that is equipped to meet externally-defined school performance objectives through effective leadership and efficient practice (Hall, Gunter and Bragg 2013); and it is assumed that the measuring of school performance which accountability practices demand will produce the requisite professional identity. In Weberian sociological terms, this identity can be thought of as an ideal type or an abstraction located at one pole of a continuum against which empirical instances can be assessed; the abstraction at the opposing pole would be the senior school leader who either fails to meet such performance objectives or who achieves them through illegitimate means. Proponents of a discourse of comparative evaluation cannot readily acknowledge the existence of this opposing pole without undermining its foundational assumption that appropriate professional behaviours and identities can be engineered. Consequently, acknowledgement of any failure to conform to the desired ideal type is more likely to invite moral judgement and the invoking of an economy of moral worth (Popkewitz 1984, 177). 'Off-rolling' suggests unquestioning adherence to one socio-political objective at the expense of another, and senior leaders who cannot deliver both satisfactory academic performance in their schools and inclusivity are deemed to be morally reprehensible.

Political expressions of moral outrage serve to distract attention from conditions of sustained and chronic under-funding of the educational inclusion agenda and the prioritising of an alternative discourse that links academic excellence to national performance within a globalised late capitalist economic system.

\section{Fabricating professional identities}

Whilst there is a substantial published literature on permanent and fixed term school exclusion, e.g. Department for Education and Skills (2006), Gill et al. (2017), Parsons (1999), the longer term impact of formal exclusion on children and young people is an underresearched area. Similarly, little is known about the affective dimension of senior school leaders' participation in exclusionary practices and the consequences for their professional identities. This dimension could be hypothesised to include dissonance between deeply-held pedagogic values and governmental pressures on senior school leaders to optimise school performance data in a marketised education performance culture (Ball 2001). Further research, specifically amongst senior school leaders, is required to explore these issues. Moore and Clarke $(2016,666)$ suggest that such dissonance is made tolerable by a discourse of professionalism that is combined with a 'cruel optimism' whereby the teaching profession is persuaded to enact policies that conflict with cherished values in the hope that longer term objectives will be realised. Those who are committed to educational inclusion and social justice may, for example, experience disappointment and frustration at the slow pace of 
change. Optimism here can be particularly cruel since senior school leaders are increasingly 'responsibilised' (Foucault 1982, 781) through a discourse of change agency and change management, imported from non-educational sectors, in which they are fabricated (Ball 2001; Popkewitz 2013, 439; Anderson and Cohen 2015, 13) as change agents who can elect to work for social justice and an inclusive education system regardless of the wider socio-political and economic context (Done and Murphy 2016, 9). Such developments encapsulate a key feature of neoliberal governmentality; 'new accountabilities', initiated and overseen by central government, are repeatedly introduced (DfE 2019a) whilst at the same time individual choice or agency is valorised and the role of professional judgement in formal exclusionary processes is endorsed (DfE 2019b).

It is possible that the sort of dissonance described above is felt particularly acutely by some senior leaders, given their ultimate responsibility for student, teacher and school performance, and the reputational damage that results from a school's poor performance in high-stakes testing, loss of market position or negative evaluation at external inspection. It has been argued, however, that the process of neoliberalising educational reform in recent decades has not only changed what educators 'do' but also 'who they are' (Ball 2003, 215), implying a shift in pedagogic values and professional identities and their alignment with a hegemonic political discourse that demands excellence and the raising of academic standards (Clarke 2013, 229). Clarke (2013) analyses the affective potential of neoliberal discourse and its capacity to induce pleasure as well as pain, and it is suggested that the 'terrors of performativity' (Ball 2003) or pressures associated with mandated and centralised accountability practices are accompanied by an economy of 'fantasy and enjoyment' (Clarke 2013, 229). Similarly, Anderson and Cohen $(2015,12)$ argue that neoliberal discourses foster conformity by appealing to our 'deep frames'. These frames manifest as a 'common sense' of education comprising taken-for-granted and, therefore, uncontested assumptions (Popkewitz 2013, 443; Done and Andrews 2019). Competitive individualism and the market order (competition in an ostensibly free market as the only viable means of resource allocation) are two such deeply rooted frames which imply enjoyment or gratification at outperforming others. Although Anderson and Cohen (2015) are able to cite examples in the U.S. of valuedriven resistance to a neoliberalised education system and centralised accountability, the affective power of such frames may explain why senior school leaders in England seemingly accept the vilification of colleagues whose schools do not achieve recognition as high performers; and why the prioritising of academic performance in a political standards agenda so often goes unquestioned.

Once the affective power of competitive neoliberal practices has been recognised it would perhaps make more sense to conceptualise the discursive production of a neoliberal professional identity as a co-fabrication where some level of emotional investment in competitive practices can be assumed. Conversely, it seems reasonable to question whether those leading schools that perform poorly in high stakes testing and consumer-orientated performance league tables are as emotionally invested in the competitive market order. These schools are likely to be situated in areas of high socio-economic deprivation and have much higher proportions of students who are classified as disadvantaged, as belonging to certain minority groups, or on the SEND register (DfE 2019b). Senior school leaders in such settings cannot simply privilege academic performance and neglect other aspects of their students' lives and the socio-economic conditions within their communities. Yet neither can they ignore governmental demands to deliver specified degrees of academic progress as to do so would risk a negative inspection rating and reputational damage to themselves and their school. Differing positions in school performance league tables and marked differences in the local contexts of schools means that senior school leaders' responses to a politicised educational inclusion agenda are likely to be complex. 
Despite such complexity, three 'kinds' of professional identity can be identified that are currently in circulation within public and governmental discourse relating to 'off rolling'. As previously mentioned, two are pejorative and, ostensibly but questionably, diagnostic - the system gamer and poor behaviour manager; these are discussed below. The third fabricated professional identity effectively proposes a solution to the malpractice of the system gamer and the underperformance of the poor behaviour manager; this is the best practice exemplar and we begin the following section on our proposed typology of professional identities pertaining to 'off rolling' with an outline of this fabricated identity.

\section{Proposed typology}

\section{The best practice exemplar}

The sharing of 'best practice' is integral to neoliberal governance as a feature of 'soft law' (Kröger 2016; Terpan 2015); it serves a normative function, facilitating policy implementation across divergent settings but raises questions around professional autonomy and the determination of what constitutes 'best practice'. It implies, simultaneously, a recognition and a denial of the importance of the contextual factors that affect senior school leaders and their staff and pupils. It appeals to the 'deep frame' (Anderson and Cohen 2015, 12) of competitive individualism and is seductive in its simplicity or lack of specificity obscuring, as it does, the political processes through which 'best' is determined. It has, as Popkewitz $(2013,443)$ would argue, acquired a taken-for-granted status within political discourse and educational discourse directed towards practitioners. All of these features are intensified when specific schools or senior school leaders are presented or promoted as exemplifying 'best practice' rather than simply sharing it. The professional autonomy which the Timpson Review (DfE 2019a) endorses is not a freedom to engage in localised experimentation and evolve school-specific strategies but, instead, an invitation to organise the implementation of initiatives adopted elsewhere and sanctioned by those with limited or no direct experience of the challenges that confront many schools.

Given the interest taken in behaviour in schools by successive governments and now evidenced in the government response (DfE 2019b, 8) to Timpson (DfE 2019a), it is unsurprising that 'best practice' exemplars are to be mobilised in the context of behaviour management and inclusive practice. The former involves a $£ 10$ million investment in 'behaviour support networks' in which 'lead schools, recognised for their excellent behaviour management, working alongside a team of experts' will target schools 'that want to turnaround their behaviour and reduce low-level disruption' in order to effect 'cultural changes' (DfE 2019b, 8). Exemplars of 'best practice' in the field of SEND will be required for similar reasons but it should be noted here that not all Special Educational Needs Coordinators (SENCos) are senior leaders able to transform their school cultures or set school priorities. In the latter scenario, senior school leaders may find that SENCos, regardless of status and at the government's request (DfE 2019a, 2019b), will increasingly position themselves as exemplars of inclusive classroom practice and as equipped to offer 'in-house' training in therapeutic discourses which provide over-simplified aetiologies of problematic behaviour. The disciplinary force of 'best practice' exemplars here is to be reinforced by the importation of alleged expertise in non-educational discourses drawn quite often from the fields of psychology and neuroscience. An ascendant regime of truth is evolving in which, for example, a popularised neuroscience is being framed as providing an incontestable foundation for pedagogic practice and therefore as informing 'best' school and classroom practice (Ball 2017).

\section{The system gamer}

Another assumption which is now well-established is that 'off-rolling' is a form of 'gaming' and a function of the pressure on schools to maintain or improve their performance 
within national and local league tables (Ofsted 2019b, 50). Data analysis undertaken by the FFT Education Datalab prompted both the suggestion that 'losing pupils is one of the ways in which secondary league tables are still susceptible to gaming' and questions addressed directly to the Department for Education (Nye 2017). One question concerned the financial constraints on Local Authorities and their reduced capacity to follow up on pupils who are permanently excluded from school or who leave school prematurely; excluded pupils must, by law, be provided with an alternative education within several days of their exclusion but authorities may now be unable to fulfil their legal responsibility in this area. Another question raised the possibility that schools should be required to include outcome data relating to pupils that previously spent time with them in their performance calculations in order to discourage 'off-rolling' (Nye 2017).

Progress 8 has been criticised by Ofsted (2019b, 2019c) for narrowing the curriculum to the detriment of pupils who would benefit most from the availability of a broader range of subjects. FFT Education Datalab's focus has, however, been on demonstrating the significant impact that 'off-rolling' can have on school-level Progress 8 data (Nye 2017). Thomson (2018) subsequently endorsed the capping of 'outliers' in proposed changes to Progress 8 methodology (DfE 2019c), arguing that this 'will go some way to addressing perhaps the most perverse incentive in Progress 8, namely to manage such pupils off-roll before the January of Year 11'. The weighting of scores for literacy and numeracy within Progress 8 methodology has also been criticised for incentivising exclusionary practices. Such weighting means that a school's overall performance data can be adversely affected by only one or two pupils (Nye 2017).

\section{The poor behaviour manager}

A further assumption which has also already gained traction is that 'off-rolling' implies a failure in behavioural management within schools (Ofsted 2019b), evoking the now familiar tendency to blame teachers and senior school management where empirical events apparently contradict hegemonic political discourses. Senior school leaders that decide to exclude students with SEND on behavioural grounds risk accusations that they are inhibiting progress towards the mandated inclusive educational system by sanctioning or, indeed, engineering the removal of pupils whose behaviour is excessively disruptive. The parliamentary response of Damien Hinds (Secretary of State for Education) (British Broadcasting Corporation [BBC] 12 May 2019) to publication of the Timpson Review (DfE 2019a) was notable in that it highlighted existing government initiatives around behaviour in schools and the modest increase in funding to be made available to extend such initiatives. However, a survey of teachers, head teachers and deputy head teachers commissioned by Ofsted (YouGov 2019) indicates that reports of poor behaviour are frequently exaggerated in order to legitimise and facilitate a student's removal from the school roll for non-behavioural reasons. (It should be noted that only one head teacher was subsequently interviewed).

Planned training in behavioural management will include the raising of awareness of the underlying causes of highly disruptive behaviour (which may include the physical assault of teachers or other students) such as psychological trauma and attachment issues (DfE 2019a, 13), evoking arguments that governmental pressure to improve academic performance has been accompanied by an ill-founded therapeutisation of education (MacNaughton 2014; Zembylas 2016).

Assumed deficits in knowledge of alternative strategies for reducing disruptive behaviour are to be addressed through revisions to teacher training and continuing professional development; the expectation is that mandatory training in behaviour management during ITT (initial teacher training) and its embedding in the Early Career Framework will ensure a sufficiently skilled workforce and reduction in disruptive behaviour (DfE 2019a, 13; DfE $2019 b, 8)$. Earlier government reports suggest that senior leaders would appreciate support and training in whole-school strategies to deliver 'positive behaviour cultures' (DfE 2019b, 8, 
14). The government is also to provide clearer guidance on behaviour management to assist decision-making around exclusion (DfE 2019b). There is to be an increase in the high needs block funding (DfE 2019a, 59) but it is open to question whether the latter will reduce the budgetary constraints that, for example, are preventing schools from employing teaching assistants to support children with complex needs who are at risk of being 'off-rolled' for behavioural reasons.

\section{Conclusions}

The mandated centralised data-based accountability practices that define the neoliberal performance culture in education afford diminishing opportunities for the reassertion of professional judgement and development of community-orientated advocacy leadership despite discourses of entrepreneurialism and change agency (Anderson and Cohen 2015) and, in the context of school exclusion in England, support for senior school leaders' autonomous decision-making (DfE 2019b). Increasing levels of school exclusion and suspicions of the illegal removal of particular categories of student from school rolls has prompted moral outrage and concerns around inclusion, and the discursive constitution of deviant school leader identities. In this paper, we have outlined a typology that includes such identities but also a novel professional identity of 'best practice' exemplar. The latter, we have suggested, has a particularly powerful affective power for schools identified as 'leading' and for SENCos whose priority is implementation of a political inclusion agenda; it can also be read as potentially divisive and designed to induce shame by highlighting alleged deficiencies regardless of context. The recent recommendation that schools suspected of engaging in 'off rolling' should be publicly 'named and shamed' (The Times 2019) assumes that schools are not currently subject to the use of shame as a disciplinary device and that senior school leaders are shameless in their efforts to avoid reputational damage to their schools. We have questioned this assumption and adopted an alternative view of 'off rolling' that might be characterised as contextual roll management in acknowledgement of the historical and more recent socio-political and economic conditions within which senior school leaders must practice. Slee $(2019,1)$ refers to 'the deep structure of social exclusion that is represented in and reproduced by schooling'; however, it should be recognised that exclusionary school practices, legal and otherwise, reflect political priorities and a hegemonic discourse around academic attainment and its contribution to national economic performance within a globalised capitalist economic system (Apple 2005; Slee 2018).

The political inclusion agenda can be construed as a response to the post-war fiscal crisis in western nations and it is unlikely to be abandoned. Educational inclusion serves an economic purpose related to the viability of the neoliberal state. Hence, as Slee $(2019,1)$ states, 'While inclusive education and the establishment of belonging for the diverse range of students who seek enrolment and successful participation in school is a challenging ambition, it is a first order requirement for sustainable futures'. Consequently, sustainability in neoliberal education policy discourse has become a matter of 'responsibilising' teachers and senior school leaders to deliver varied political agendas regardless of the wider socio-political and economic context (Done, Murphy and Knowler 2015). This context includes rapid reform of the public sector, the marketisation of the education sector and the intensification of accountability practices (Gunter, Hall and Mills 2014); it has been accompanied by initiatives designed to re-engineer professional identities and the nature of senior leadership in schools (Hall, Gunter and Bragg 2013). These developments have coincided with a discourse around inclusive education which requires 'mainstream' schools to provide for students with varied and complex 'needs', and more recently with a fiscal crisis that has reduced the public funds available to ensure meaningful inclusion (Done and Murphy 2016). Schools must negotiate an academic standards agenda that is linked in political discourse to the fate of the national 
economy and deliver an equally politicised inclusion agenda that is increasingly underfunded.

Attention to league table performance is integral to the marketisation of education as it informs consumer choice and the disciplining of poorly performing schools. We would characterise Ofsted's (2019c) proposed changes to its inspection framework as a compounding of the pressures upon schools and senior leaders to deliver divergent governmental agendas in the absence of contextual change. The government response to Timpson (DfE 2019b, 2019a) acknowledges that government policies can have unintended consequences and the risk that new policies may create perverse incentives to exclude; but, of course, neither the tension between competing policy logics or the existence of a hegemonic logic that influences professional identity and school practices is recognised. To do so would contradict the neoliberal discourses which have informed the key educational reforms of recent decades. Instead, both the Timpson Review (DfE 2019a) and the government's response (DfE 2019b) serve to reinforce the compartmentalisation of policy areas and prioritisation of academic performance whilst purporting to address social injustices. The scope for resistance to education policies which contradict professional values related to equity and community service is limited given current under-funding of the inclusion agenda and the pressure on senior school leaders to prioritise demonstrations of progress in academic attainment.

The fabricated and stereotypical images of 'system gamer', 'poor behaviour manager' and - most recently, 'best practice exemplar', which we have identified are products of a normative discourse that neglects key issues. In the absence of wider socio-political change the professional identities of senior school leaders will remain a site of contestation. What is needed is research into senior school leaders' perceptions of practice priorities, their selfperceptions and negotiation of fabricated professional identities rather than further speculation about contributory factors and declarations of moral outrage around 'off rolling'. Instead of identifying an aberrant and abject sub-population of senior school leaders that must be punished or remediated, our research is intended to generate a better understanding of contextual roll management as a novel historical practice fostered by tensions between policy agendas against a backdrop of under-resourcing. We are seeking to explore the potentially profound implications of this situation for the professional identities of senior school leaders.

\section{Acknowledgements}

The authors would like to thank the reviewers of this paper for their invaluable guidance.

\section{Data Availability}

Data sharing is not applicable to this article as no new data were created or analysed in this study.

\section{Ethical Guidelines}

The prospective research referred to in this paper has been approved by the Ethics Committee of the University of Exeter and adheres to British Educational Research Association (2018) ethical guidelines.

\section{Conflict of Interest}

There are no conflicts of interest associated with this paper. 


\section{References}

Anderson, G. (2009) Advocacy leadership: toward a post-reform agenda (New York, NY, Routledge).

Anderson, G. \& Cohen, M. I. (2015) Redesigning the identities of teachers and leaders: a framework for studying new professionalism and educator resistance, Education Policy Analysis Archives, 23(85). http://dx.doi.org/10.14507/epaa.v23.2086.

Apple, M.W. (1995) Education and power, $2^{\text {nd }}$ edition (New York, Routledge).

Apple, M.W. (2005) Education, markets and an audit culture, Critical Quarterly, 47(2), 11 29.

Apple, M.W. (2014) Foreword, in Gunter, H.M., Hall, D. \& Mills, C. (Eds.) Education policy research: design and practice at a time of rapid reform, vii-xiii (London, Bloomsbury).

Ball, S. (2001) Performativities and fabrications in the education economy: towards the performative society, in D. Gleason \& C. Husbands (Eds.) The performing school: managing, teaching and learning in a performance culture, 210-226, (London, Routledge Falmer).

Ball, S. J. (2003). The teacher's soul and the terrors of performativity, Journal of Education Policy, 18(2), 215-228.

Ball, S.J. (2017) Foucault as educator. London: Springer.

Ball, S.J. \& Junemann, C. (2011) Education policy and philanthropy: the changing landscape of English education governance, International Journal of Public Administration, 34, 646-661.

Clarke, M. (2013) Terror/enjoyment: performativity, resistance and the teacher's psyche, London Review of Education 11(3), 229-238.

Department for Education (2014) Children and Families Act 2014 (London, HMSO).

Department for Education (2016) Progress 8: how Progress 8 and Attainment 8 measures are calculated (London, DfE).

Department for Education (2017) Secondary accountability measures: guide (London, DfE).

Department for Education (2019a) The Timpson review of school exclusion: government response. Available online at:

https://assets.publishing.service.gov.uk/government/uploads/system/uploads/attachment_data /file/800676/Timpson_review_of_school_exclusion_government_response.pdf (accessed 7 May 2019).

Department for Education (2019b) Timpson review of school exclusion (London, DfE). Available online at:

https://assets.publishing.service.gov.uk/government/uploads/system/uploads/attachment_data /file/799979/Timpson_review_of_school_exclusion.pdf (accessed 8 May 2019). 
Department for Education (2019c) Secondary accountability measures: guide for maintained secondary schools, academies and free schools (London, DfE).

Department for Education and Skills (2006) Working to prevent the social exclusion of children and young people: final lessons from the National Evaluation of the Children's Fund (Nottingham, DfES).

Done, E.J \& Andrews, M. (2019) How inclusion became exclusion: policy, teachers and inclusive education, Journal of Education Policy, published online 20 March 2019. https://doi.org/10.1080/02680939.2018.1552763

Done, E.J., Murphy, M. \& Knowler, H. (2015) Mandatory accreditation for special educational needs co-ordinators: biopolitics, neoliberal managerialism and the DeleuzoGuattarian 'war machine', Journal of Education Policy, 30, 86-100.

Done, E.J. \& Murphy, M. (2018) The responsibilisation of teachers: a neoliberal solution to the problem of inclusion, Discourse: Studies in the Cultural Politics of Education, 39, 142155.

Foucault, M. (1977) Discipline and punish. New York: Vintage.

Foucault, M. (1982) The subject and power, Critical Inquiry, 8(Summer1982), 777-795.

Foucault, M. (2008) The birth of biopolitics: lectures at the Collège de France 1978-1979 (New York, NY, Palgrave).

Gill, K., Quilter-Pinner, H. \& Swift, D. (2017) Making the difference: breaking the link between school exclusion and social exclusion. Progressive Policy Think Tank. Available online at: https://www.ippr.org/files/2017-10/making-the-difference-summary-october2017.pdf (accessed 2 February 2019).

Gunter, H., Hall, D. \& Mills, C. (2014) Education policy research: design and practice at a time of rapid reform (London, Bloomsbury).

Hacking, I. (2006) Making up people, London Review of Books, 28(16), 23-26.

Hall, D., Gunter, H. \& Bragg, J. (2013) Leadership, new public management and the remodelling and regulation of teacher identities, International Journal of Leadership in Education, 16(2), 173-190, doi: 10.1080/13603124.2012.688875

House of Commons Education Committee (2018) Forgotten children: alternative provision and the scandal of ever increasing exclusions: Fifth report of session 2017-2019 (London, $\mathrm{HoC})$.

Kröger, S. (2009) The open method of coordination: underconceptualisation, overdetermination, depoliticisation and beyond, in Kröger, S. (Ed.) What we have learnt: advances, pitfalls and remaining questions in OMC research, European Integration Online Papers (EIoP), Special Issue 1, Vol. 13, Art. 5, http://eiop.or.at/eiop/texte/2009-005a.htm. 
MacNaughton, G. (2004) The politics of logic in early childhood research: a case of the brain, hard facts, trees and rhizomes, http://files.eric.ed.gov/fulltext/EJ689638.pdf.

Moore, A., \& Clarke, M. (2016) 'Cruel optimism': teacher attachment to professionalism in an era of performativity, Journal of Education Policy, 31, 666-677,

doi:10.1080/02680939.2016.1160293

Munn, P. \& Lloyd, G. (2005) Exclusion and excluded pupils, British Education Research Journal, 31(2), 205-221.

Nye, P. (2017) Who's left: three questions for the Department for Education from our work. Blog post, 31 January 2017. Available online at:

https://ffteducationdatalab.org.uk/2017/01/whos-left-three-questions-for-the-department-foreducation-from-our-work/ (accessed 5 February 2019).

Office of the Schools Adjudicator (2017) Annual report September 2017 to August 2018, Available online at: https://www.gov.uk/government/news/annual-report-of-the-chiefschools-adjudicator-for-england--3 (accessed 3 February 2019).

Ofsted (2018) 'off-rolling': using data to see a fuller picture. Available online at:

https://educationinspection.blog.gov.uk/2018/06/26/'off-rolling'-using-data-to-see-a-fullerpicture/ (accessed 2 February 2019).

Ofsted (2019a) Off-rolling: an update on recent analysis. Available online at:

https://educationinspection.blog.gov.uk/2019/09/06/off-rolling-an-update-on-recent-analysis/ (accessed 20 September 2019).

Ofsted (2019b) The annual report of Her Majesty's Chief Inspector of Education, Children's Services and Skills 2017 / 2018. Available online at: https://www.gov.uk/government/publications/ofsted-annual-report-201718-educationchildrens-services-and-skills (accessed 10 January 2019).

Ofsted (2019c) Education inspection framework 2019: DRAFT: Equality, diversity and inclusion statement. Available online at:

https://assets.publishing.service.gov.uk/government/uploads/system/uploads/attachment_data /file/771294/EIF_EDI_draft_statement_for_consultation_140119.pdf (accessed 10 May 2019).

Parsons, C. (1999) Education, exclusion and citizen (New York, Routledge).

Popkewitz, T. (1984) Paradigm and ideology in educational research: the social functions of the intellectual (Basingstoke, Taylor Francis).

Popkewitz, T. (1991) A political sociology of educational reform: power/knowledge in teaching, teacher education, and research (New York, Teachers College Press).

Popkewitz, T. (2013) The sociology of education as the history of the present: fabrication, difference and abjection, Discourse: Studies in the Cultural Politics of Education, 34:3, 439456, doi: 10.1080/01596306.2012.717195 
Sellman, E., Bedward, J., Cole, T. \& Daniels, H. (2002) A socio-cultural approach to exclusion, British Education Research Journal, 28(6), 889-900.

Slee, R. (2018) Defining the scope of inclusive education. Paper commissioned for the 2020 Global Education Monitoring Report: inclusion and education (Paris, UNESCO).

Slee, R. (2019) Belonging in an age of exclusion, International Journal of Inclusive Education. Published online 9 April 2019, doi: 10.1080/13603116.2019.1602366

Slee, R. \& Allan, J. (2001) Excluding the included: a reconsideration of inclusive education, International Studies in Sociology of Education 11(2), 179-192.

Terpan, F. (2015) Soft law in the European Union: the changing nature of EU law, European Law Journal, 21(1), 68-96.

Tickle, L. (2019) 'Cleansed by cuts': schools refuse places to special needs pupils: families seek judicial review against UK government as funding cuts force headteachers to limit SEN admissions, The Guardian, 7 May 2019.

Thrupp, M. (1998) Exploring the politics of blame: school inspection and its contestation in New Zealand and England, Comparative Education 34(2), 195-209.

The Times (2019) Schools that off-roll pupils need to be named and shamed, by David Laws. 18 April 2019.

Thomson, D. (2018) Progress 8: what if we started at the beginning? Blog post 27 April 2018, https://ffteducationdatalab.org.uk/2018/04/progress-8-what-if-we-started-at-thebeginning/

YouGov (on behalf of Ofsted) (2019) Exploring the issue of 'off-rolling'. Available online at: https://www.gov.uk/government/news/teachers-say-parents-need-help-to-resist-'off-rolling'pressure (accessed 10 May 2019).

Zembylas, M. (2016) The therapisation of social justice as an emotional regime: implications for critical education, Journal of Professional Capital and Community, 1(4), 286-301. 